\title{
A comparison of the effectiveness of group reality therapy and positive psychotherapy on irrational beliefs and psychological hardiness in brilliant talent students
}

\author{
Safar Abdi ${ }^{1}$, Tayebeh Sharifi ${ }^{2 *}$, Ahmad Qazanfari ${ }^{2}$, Kamal Solati $^{3,2}$ \\ ${ }^{1}$ Faculty of Humanities, Shahrekord Branch, Islamic Azad University, Shahrekord, Iran \\ ${ }^{2}$ Department of Psychology, Faculty of Humanities, Shahrekord Branch, Islamic Azad University, Shahrekord, Iran \\ ${ }^{3}$ Department of Psychiatry, Faculty of Medical, Shahrekord University of Medical Sciences, Iran
}

*Corresponding Author: Tayebeh Sharifi, Assistant Professor, Department of Psychology, Faculty of Humanities, Shahrekord Branch, Islamic Azad University, Shahrekord, Iran, E-mail: sharifi_ta@yahoo.com

\begin{abstract}
Background and aims: Irrational beliefs in brilliant talent students can influence their psychological hardiness and lead to adverse social and academic outcomes. The present study mainly aimed to compare the effectiveness of group reality therapy and positive psychotherapy in improving the irrational beliefs and psychological hardiness of male brilliant talent high school students in Shahrekord during 2017. Methods: The present experimental research, used pretest and posttest design including intervention and control groups. The study population included all the male gifted students in Shahrekord $(\mathrm{N}=276)$ who were first screened and then, 60 individuals were selected by convenience random sampling. Next, the individuals were assigned a number and then divided into two experimental groups (each containing 20 students) and one control group (including 20 students) using a random number table. Afterward, group reality therapy and positive psychotherapy interventions were performed within eight and ten weeks for the experimental groups, respectively. In addition, Jones Irrational Beliefs Test (IBT) and Kobasa's Psychological Hardiness Scale were employed to data collection. Six months after post-test implementation, the students were followed up. Finally, the data were analyzed using repeated-measures ANOVA and Bonferroni post hoc test.

Results: The findings revealed that group reality therapy and positive psychotherapy led to a decrease in irrational beliefs while such therapies improved psychological hardiness in brilliant talent students $(P<0.001)$. Conversely, the results of the post-hoc test indicated no significant difference between the effects of group reality therapy and positive psychotherapy on irrational beliefs and psychological hardiness in brilliant talent students $(P>0.05)$.

Conclusion: In general, group reality therapy and positive psychotherapy reduced irrational beliefs whereas they improved psychological hardiness of the brilliant talent students and therefore, these therapies can be used as effective interventions for the intended population. Keywords: Reality therapy; Positive psychotherapy; Irrational beliefs; Psychological hardiness; Brilliant talents
\end{abstract}

Received: 27 June 2018, Accepted: 23 December 2018, ePublished: 19 January 2019

\section{Introduction}

Obviously, the most important assets of every society are its human resources, especially brilliant talent students have a substantial part in this regard. Therefore, every society which aims to grow and develop should pay special attention to its brilliant talent students and prepare the grounds for their utmost progress. In addition, one of the most influential factors in this field is the inability of such students to perfectly act based on their mental capacity and the grade of education (1). This phenomenon is known as the academic underachievement of brilliant talent students (2). This is not a new phenomenon as Terman repeatedly addressed it in his early studies (3). Further, many theorists focused on the determinants of academic achievement. Various factors including psychological hardiness contribute to this phenomenon (4). Furthermore, psychological hardiness was stipulated by Kobasa (5) based on the existential psychology theories about the degree of appropriate life. He defined psychological hardiness as a combination of beliefs about oneself and the world and argued that it contains commitment, control, and challenge components (6). Therefore, an individual with a high level of psychological hardiness can control the incidents, considers the psychological stressors to be changeable, holds himself/herself accountable for his/her actions, and believe that change is an exciting challenge and an aspect of life (7). Additionally, such hardiness can increase a person's ability to cope with psychological stress and protect against pressure and stress. In addition, it can be defined as a tendency to maintain health and improve function despite stressful conditions (8).

Different factors can influence the brilliant talent 
students' psychological hardiness including irrational beliefs (9). Beliefs are the rules by which the individual interprets his/her experiences. Therefore, the ability to predict personal experiences and give meaning to them is necessary for normal functioning. However, some assumptions are inflexible, extremist, resistant to change, and thus ineffective. When ineffective assumptions are activated, they trigger negative and self-suggesting thoughts. This cycle eventually leads to the development of irrational beliefs (10). These beliefs, which are strict and prejudicial expectations (11) include the need for approval, high self-expectations, tendency to blame, reaction to failures, emotional irresponsibility (emotional control), excessive worry accompanied by anxiety (anxious attention), avoiding problems, dependence, helplessness to change, and perfectionism (12).

Numerous psychological and educational interventions are used to improve the academic, psychological, social, and emotional performance of the brilliant talent students. Group reality therapy is one of the effective methods to improve the psychological state of these students. Glasser's approach stresses exposure to reality, responsibility, and evaluation of the correctness or incorrectness of the behaviors. Based on this approach, the individual is responsible for his or her own actions, thoughts, and emotions while he/she is not the victim of his past or the present unless he/she selects such a condition. This therapeutic approach is applied to both normal and abnormal behaviors and employed to develop the appropriate educational approaches (13). It primarily aims to help the individuals satisfy their needs such as the need for power, achievement, freedom, independence, and entertainment. Further, the main notions of this approach include identity, personality, responsibility, adaptive behavior, and ultimately, the realistic and rational treatment of problems and difficulties (14).

In this regard, Golestan and Mirfakhraei indicated that Glasser's reality therapy is effective in improving the ineffective attitudes and rumination in patients with multiple sclerosis (15). Furthermore, Maldari and Masoudi reported that group reality therapy reduces the irrational beliefs in mothers with exceptional children (16). In another study, Mesmanabadi et al found that reality therapy-based group counseling increases resilience and positive affectivity while it reduces anger, depressive moods, and anxiety in mothers with disabled children (17). Additionally, Safavi Gordini et al emphasized the effect of this therapy on the psychological hardiness of high school students (18). Peterson et al (19) argued that training of the choice theory and reality therapy contribute to the development and maintenance of a positive self-concept in the Taiwanese university students. In his research, Kim (20) found that reality therapy caused positive changes to self-control, self-esteem, and stress reduction in patients.

In addition, positive psychotherapy is another therapeutic and interventional approach which can be applied for brilliant talent students. In fact, positive psychotherapy training can help the individual focus on the future, becomes free of negative retrospection and instantaneous reactions, and redoubles his/her efforts to attain his/her transcendental goals. It fosters futurism in the individual, leading to several positive consequences (21). Positive psychology was first introduced by Seligman in the late 1990 s and in the early 21 st century. One of the major goals of this approach is to highlight the human's positive personality traits instead of the morbid and pathological aspects. Further, positive psychology stresses the human's abilities and strengths such as the ability to live happily and enjoy life, problem-solving abilities, and optimism rather than the human's disabilities and weaknesses (22). As a result, Seligman managed to formulate the major notions of positive psychology through the fusion of the learned helplessness and attribution theories. If helplessness can be learned then, it is possible to learn the positive emotional, cognitive, and attitudinal aspects such as optimism and happiness by changing the attribution style (23). Individuals with positive attitudes enjoy life comparatively more and are healthier and believe that failure is only a transient incidence whose causes are only limited to that specific failure (24). Such individuals do not become furious after a failure. Instead, they confront the unpleasant condition and make more attempts (25). The results of previous research represent the effectiveness of positive psychotherapy in improving irrational beliefs (26) and psychological hardiness (27).

Different studies emphasized the effectiveness of group reality therapy and positive psychotherapy interventions in reducing irrational beliefs whereas increasing psychological hardiness. However, there is the lack of research on the effects of both interventions on the abovementioned constructs among the gifted students, the vast metacognitive knowledge of the exceptionally talented students, the role of responsibility-driven reality therapy in one's own thoughts and behaviors, the emphasis of positive psychotherapy on the role of positive aspects and emotions in developing a metacognitive insight, and the necessity of identifying the best intervention in terms of time and costs. Accordingly, the current study attempted to compare the effect of the 2 methods on the irrational beliefs and psychological hardiness of the gifted students. The researcher, therefore, sought to answer the following research question: Is there a significant difference between the effects of group reality therapy and positive psychotherapy on the irrational beliefs and psychological hardiness of the male brilliant talent, students at the second-grade high school of Shabrekord?

\section{Materials and Methods}

The current experimental study was a pretest-posttest with the control group and a follow-up period of six 
months. The study population encompassed all the male, brilliant talent high school students in Shahrekord $(\mathrm{N}=276)$. The sample size was estimated at 15 for each group using Cohen Table with the effect size of 0.5 and the test power of 0.75 . Furthermore, 20 students were considered for each group in order to validate the results. Therefore, the ethics code (Ir.Iau.Shk.Rec.1397.003) and a license were obtained from the provincial education organization. Then, after screening, 150 students were selected who then completed Jones Irrational Beliefs Test (IBT) and Kobasa’s Psychological Hardiness Scale. Next, 60 students out of those who obtained a score of over 60 on the IBT and below 75 on the psychological hardiness scale were selected by convenience random sampling technique for inclusion in three groups. Afterward, all the students were assigned a number. Then, 20 students were assigned to each of the three groups (two experimental and one control group) using random numbers and based on the criteria for entering the study. Research entry criteria included students who were studying at the brilliant talent center, personal willingness to participate in the research, lack of acute or chronic mental disorders (based on the counseling case), lack of using psychiatric drugs during the past 3 months (through questioning the clients). Additionally, the exclusion criteria were lack of cooperation, failure to perform assignments given during the meetings, absence in more than 2 sessions, and withdrawal from the study. Next, Glasser's group reality therapy (28) and Seligman and Csikszentmihalyi's positive psychotherapy (29) interventions were conducted on intervention group within 2-hour weekly sessions for eight and ten weeks, respectively. A summary of the two interventions is presented in Table 1. The control group underwent no intervention. In the post-test, the irrational beliefs and psychological hardiness were measured in all three groups. Six months after the post-test, the dependent variables were estimated once more for all three groups.

\section{Irrational beliefs test}

This test included 100 items regarding the individual's beliefs and feelings about things which existed or not for them. This instrument measured the following subscales: need for approval (items 1, 11, 21, 31, 41, 51, 61, 71, 81, and 91), high self-expectations (items $2,12,22,32$, $42,52,62,72,82$, and 92), tendency to blame (items $3,13,23,33,43,53,63,73,83$ and 93 ), reaction to failure (4, 14, 24, 34, 44, 54, 64, 74, 84, 94), emotional irresponsibility (items 5, 15, 25, 35, 45, 55, 65, 75, 85, and 95), excessive anxiety $(6,16,26,36,46,56,66,76$, 86, 96), avoiding problems (items $7,17,27,37,47,57$, $67,77,87$, and 97), dependence (items $8,18,28,38,48$, $58,68,78,88$, and 98), helplessness to change (items 9 , 19, 29, 39, 49, 59, 69, 79, 89, and 99), and perfectionism (items 10, 20, 30, 40, 50, 60, 70, 80, 90, and 100). The IBT items were rated on a 5 -point Likert-type scale as follows: Strongly disagree (1), Partly disagree (2), Neutral (3), Partly agree (4), and Strongly agree (5). The scores on each subscale and the total scale ranged from 10 to 50 and from 100 to 500, respectively. The items regarding each subscale are listed below. The sum of the scores of the items regarding each subscale and the sum of the subscales' scores represented the total score on that subscale and the total score on irrational beliefs, respectively. Jones obtained a validity of 0.92 and reliability of $0.66-0.80$ for the 10 subscales using the test-retest method (30). Further, Babaei and Rezahani confirmed the validity of this test using the factor analysis method (31). The Cranach alpha coefficients calculated for the subscales of the need for approval, high self-expectations, tendency to blame, reaction to failure, emotional irresponsibility, excessive anxiety, avoiding problems, dependence, helplessness to change, perfectionism, and irrational beliefs were reported as $0.72,0.64,0.75,0.73,0.67,0.71,0.73,0.69,0.76$, 0.68 , and 0.76 , respectively.

\section{Psychological hardiness test}

Kobasa's psychological hardiness test was used to measure psychological hardiness in this study. This test, according to Kobasa, is a self-report questionnaire employed to investigate the psychological hardiness of the respondents. It encompassed 50 items and three subscales, namely, control (items 3, 4, 5, 7, 10, 13, 16, 19, 22, 25, 28, $31,34,35,42,45$, and 48), commitment (items 1, 8, $11,14,17,20,23,26,29,32,38,39,41,44,47$, and 50 ), and challenge (items $2,6,9,12,15,18,21,24,27$, $30,33,36,37,40,43,46$, and 49). The respondents' answers were rated on a 4-point Likert-type scale (i.e., Absolutely incorrect, Partly correct, Mostly correct, and Absolutely correct). The score of each item ranged from 0 to 3 , and the total score on the test was between 0 and 150. Furthermore, the sum of the scores on each subscale demonstrated the total score on that subscale and the sum of the scores on all subscales represented the total psychological hardiness score. The psychological hardiness scale (33) was translated into Persian by Narimani and Abbasi, and the face and content validity of the Persian version were calculated at 0.82 and 0.77 , respectively (34). Additionally, the research by Jamhari (35) revealed that all three subscales of the questionnaire, namely, commitment, control, and challenge had reliability coefficients of $0.72,0.68$, and 0.65 , respectively. In addition, the total reliability coefficient of the test was obtained at 0.78 . Further, the Cronbach's Alpha coefficients for the subscales commitment, control, and challenge in that study were calculated at $0.79,0.78$, and 0.75 , respectively. Finally, the Cranach's Alpha for the whole psychological hardiness test was obtained 0.79 .

After collecting the data in three phases (i.e., pretest, post-test, and follow-up), they were analyzed using descriptive and inferential statistics by the SPSS software, 
Table 1. The summary of the group reality therapy and positive psychotherapy sessions

\begin{tabular}{|c|c|c|c|c|}
\hline \multirow{2}{*}{ Session } & \multicolumn{2}{|c|}{ Group Reality Therapy } & \multicolumn{2}{|l|}{ Positive Psychotherapy } \\
\hline & Objective & Contents \& Activities & Objective & Contents \& Activities \\
\hline 1 & Introduction & $\begin{array}{l}\text { Introducing the members to each other, explaining the } \\
\text { rules and goals, establishing emotional relationships } \\
\text { among the members, and developing a sense of attachment } \\
\text { to the group among the members }\end{array}$ & $\begin{array}{l}\text { Introducing the group members } \\
\text { to each other, explaining the } \\
\text { group goals and rules, and giving } \\
\text { explanations on the training sessions }\end{array}$ & $\begin{array}{l}\text { Recording one's own } \\
\text { emotional states after } \\
\text { feeling desperate }\end{array}$ \\
\hline
\end{tabular}

Introducing the Teaching the choice theory and the five fundamental needs

choice theory (i.e., survival, love, belonging, power, freedom, and fun) and the five and their effects on human life, asking the respondents to fundasess their own needs within a week and prioritize them fundamental needs with regard to the five fundamental needs

Teaching the Teaching the identification of behavior components and components of their functions, teaching thinking, action, feeling, and

3 behavior (the their functions, teaching thinking, action, feeling, and
physiology, teaching the consolidation of the behavior notion of the total physiology, teaching the consolidation

Familiarizing the participants with the characteristics and consequences of hope and despair

Writing down the effects of positive events on the mitigation of despair

Drawing the participants' attention to their strengths

Writing down their strengths
Assessing and identifying seven destructive and maladaptive habits (i.e., baseless criticism, blaming complaining, whining, threatening, punishing, and luring), stressing the necessity of breaking the maladaptive and Creating healthy spirit required for communication

destructive habits of controlling others and replacing them with seven effective communication habits (i.e., supporting, encouraging, accepting, trusting, respecting, listening, and talking)

Teaching the self-control methods including keeping calm at the times of anger and using behavioral techniques such as deep breathing, counting up or down, and role play to manage the members in the critical situations and prevent a damage

$5 \quad$ Learning content and self-control

The group members are classified into 2- to 4-member groups to collaborate in activities such as painting and drawing. By taking part in these collaborative activities, behavior by raising the spirit of cooperation

New behavioral
planning strategies

In this session, the students learn the methods of replacing their wrong choices with the right ones. In addition, they learn how to prevent irresponsible behaviors by selecting the appropriate behaviors

Expressing one's own strengths from others' perspectives

Writing down the strengths gained within the week

Describing at least 5-10 positive experiences and memories to the members

Writing down one's own sweet memories of the week

Listening to the good experiences of the group members and drawing their strengths and positive characteristics

Interacting with each other more closely by directly expressing each other's strengths while looking at each other's eyes. one's own strengths and abilities

Practicing concentration on the good and positive sides of what they face

A list of the one's own identified strengths is prepared by himself / herself.

Writing all the positive traits identified throughout the sessions

Preparing and prioritizing all the strengths and competencies of an individual with the aid of others

Recording the events, appointing the posttest

Presenting the evidence and criteria to confirm that their most valuable and valid strengths are reliable and follow-up test dates, and thanking the members version 21. The central tendency and dispersion indices (i.e., mean and standard deviation) and repeatedmeasures analysis of variance (ANOVA) were employed for descriptive and inferential statistics, respectively. The significance level was considered $P<0.05$.

\section{Results}

The mean age of the students in the reality therapy, positive psychotherapy, and control groups was 15.70 \pm 1.41 , $14.85 \pm 1.38$, and $15.50 \pm 2.06$ years, respectively; the mean age of all the participants was $15.35 \pm 1.66$ years. As regards the academic degree, the mothers had an associate (25\%), bachelor's (25\%), master's (25\%), and doctorate (25\%) degrees in the reality therapy group. Furthermore, in the positive psychotherapy group, the mothers had an associate (25\%), bachelor's $(30 \%)$, master's $(20 \%)$, and doctorate degree $(30 \%)$. Finally, mothers in the control group held high school diploma $(10 \%)$, or associate $(10 \%)$, bachelor's (30\%), master's (25\%), and doctorate (25\%) degrees. Additionally, respecting the fathers' level of education, 
$5 \%, 10 \%, 30 \%, 30 \%$, and $25 \%$ of them in reality therapy group had high school diploma, or associate, bachelor', master's, and doctorate degrees, respectively. In addition, in the positive psychotherapy group, fathers held associate (25\%), bachelor's (25\%), master's (25\%), and doctorate (25\%) degrees. Further, in the control group, 15\%, 35\%, $25 \%$, and $25 \%$ of the fathers had an associate, bachelor's, master's, and doctorate degrees, respectively.

Table 2 demonstrates the mean and standard deviation of irrational beliefs and psychological hardiness in the two reality therapy and positive psychotherapy groups and control group in the pretest, post-test, and follow-up phases. As shown, the average scores on irrational beliefs and psychological hardiness in the two intervention groups (i.e., reality therapy and positive psychotherapy) varies in post-test and follow-up compared to those in the control group.

Before presenting the results, parametric test assumptions were used to analyze two-way analysis of variance with repeated measurements. The results of the Shapiro-Wilk test indicated that the assumption regarding the normal distribution of data existed in irrational beliefs and psychological hardiness among the intervention groups (i.e., reality therapy and positive psychotherapy) and control group in the pretest, post-test, and follow-up phases $(P>0.05)$. Furthermore, the assumption of homogeneity of variance was investigated by Levene's test. The results were not statistically significant, which represented that homogeneity of variance existed $(P>0.05)$. Additionally, based on the results of the Mauchly's test of Sphericity the assumption of sphericity was observed in irrational beliefs and psychological hardiness in the intervention and control groups $(P>0.05)$. To compare the effectiveness of group therapy and positive psychotherapy on irrational beliefs and psychological hardiness of talented students, repeated measure analysis of variance has been used.

As shown in Table 3, F is the effect of interaction between stages and groups for irrational beliefs (15.84) and psychological hardiness (45.95) which is significant at the level of 0.001 . These findings indicate that the intervention groups (i.e., the reality of therapeutic and positive psychotherapy) are in the pre-test, post-test, and follow-up.

In addition, Bonferroni's post-hoc test was employed to investigate whether the effects of group reality therapy and positive psychotherapy significantly varied respecting irrational beliefs and psychological hardiness.

The results of Table 4 represent no statistically significant difference in the mean scores between group reality therapy and positive psychotherapy groups concerning irrational beliefs and psychological hardiness. Further, the scores on irrational beliefs and psychological hardiness in reality therapy and positive psychotherapy groups are significantly different compared to those in the control group. The above findings suggest that the reality of therapy and positive psychotherapy have a significant effect on irrational beliefs and psychological hardiness while the difference between these two methods is negligible.

\section{Discussion}

The present study compared the effects of group reality therapy and positive psychotherapy on the irrational beliefs and psychological hardiness of the male brilliant talent students in Shahrekord during 2017. The results revealed that group reality therapy and positive psychotherapy influenced the irrational beliefs of these students, leading

Table 2. Mean and standard deviation of irrational beliefs and psychological hardiness of reality therapy, positive psychotherapy, and control groups

\begin{tabular}{|c|c|c|c|c|}
\hline Variables & Group & $\begin{array}{l}\text { Pre-test } \\
\text { Mean + SD }\end{array}$ & $\begin{array}{l}\text { Post-test } \\
\text { Mean + SD }\end{array}$ & $\begin{array}{l}\text { Follow-up } \\
\text { Mean + SD }\end{array}$ \\
\hline Irrational beliefs & $\begin{array}{l}\text { Reality therapy group } \\
\text { Positive psychotherapy group } \\
\text { Control group }\end{array}$ & $\begin{array}{c}326.40 \pm 21.81 \\
327.40 \pm 15.47 \\
329.53 \pm 17.26\end{array}$ & $\begin{array}{l}310.40 \pm 19.15 \\
314.46 \pm 14.99 \\
327.26 \pm 20.15\end{array}$ & $\begin{array}{l}305.13 \pm 17.65 \\
311.73 \pm 19.26 \\
333.73 \pm 19.26\end{array}$ \\
\hline Psychological hardness & $\begin{array}{l}\text { Reality therapy group } \\
\text { Positive psychotherapy group } \\
\text { Control group }\end{array}$ & $\begin{array}{l}72.20 \pm 8.32 \\
72.40 \pm 12.92 \\
69.60 \pm 7.92\end{array}$ & $\begin{array}{l}80.72 \pm 8.06 \\
81.13 \pm 11.17 \\
69.86 \pm 7.72\end{array}$ & $\begin{array}{l}82.60 \pm 7.70 \\
84 \pm 10.97 \\
69.40 \pm 8.77\end{array}$ \\
\hline
\end{tabular}

Table 3. The two-way repeated measures analysis of variance to examine the differences between the groups regarding the studied variables

\begin{tabular}{|c|c|c|c|c|c|c|c|c|}
\hline & & Sum of Squares & $d f$ & Mean Squares & $\mathbf{F}$ & $P$ value & Effect Size & Power Test \\
\hline \multirow{4}{*}{ Irrational beliefs } & Time & 3412.10 & 2 & 1706.05 & 40.15 & 0.0001 & 0.49 & 1 \\
\hline & Group & 6436.90 & 2 & 3218.45 & 6.09 & 0.005 & 0.24 & 0.9 \\
\hline & Interaction of time \& group & 2691.85 & 4 & 672.96 & 15.84 & 0.0001 & 0.43 & 1 \\
\hline & Error & 3568.71 & 84 & 42.48 & & & & \\
\hline \multirow{4}{*}{$\begin{array}{l}\text { Psychological } \\
\text { hardness }\end{array}$} & Time & 1334.44 & 2 & 667.38 & 179.22 & 0.0001 & 0.81 & 1 \\
\hline & Group & 2561.48 & 2 & 1280.74 & 5.61 & 0.007 & 0.23 & 0.87 \\
\hline & Interaction of time \& group & 684.43 & 4 & 171.10 & 45.95 & 0.0001 & 0.68 & 1 \\
\hline & Error & 312.80 & 84 & 3.72 & & & & \\
\hline
\end{tabular}


Table 4. The analysis of the differences to compare the effects of reality therapy and positive psychotherapy

\begin{tabular}{|c|c|c|c|c|c|}
\hline Variable & Phase A & Phase B & Difference in Mean Value & Standard Deviation_ & Significance Level \\
\hline \multirow{4}{*}{ Irrational beliefs } & \multirow{2}{*}{ Reality therapy } & Positive psychotherapy & -3.88 & 4.84 & 0.97 \\
\hline & & Control group & -16.20 & 4.84 & 0.005 \\
\hline & \multirow{2}{*}{ Control group } & Reality therapy & 16.30 & 4.84 & 0.005 \\
\hline & & Positive psychotherapy & 12.31 & 4.84 & 0.03 \\
\hline \multirow{4}{*}{$\begin{array}{l}\text { Psychological } \\
\text { hardiness }\end{array}$} & \multirow{2}{*}{ Reality therapy } & Positive psychotherapy & -0.66 & 3.18 & 0.99 \\
\hline & & Control group & 8.89 & 3.18 & 0.02 \\
\hline & \multirow{2}{*}{ Control group } & Reality therapy & -8.89 & 3.18 & 0.02 \\
\hline & & Positive psychotherapy & -9.55 & 3.18 & 0.01 \\
\hline
\end{tabular}

to an improvement in their irrational beliefs. Furthermore, this effect persisted in the follow-up phase. The difference in irrational beliefs between reality therapy and positive psychotherapy interventions has not yet been adequately investigated. However, many studies directly or indirectly investigated the effectiveness of these two interventions on irrational beliefs $(15,16,21,26,36-45)$.

To explain these findings, it can be argued that reality therapy brings the individuals closer to their desires and goals by inducing a change, as well as persuading and helping the individuals believe in their ability and select which behavior to perform. Additionally, the individuals adopt a rational and realistic way to their needs by adhering to this approach. In addition, reality therapy teaches the individual that he/she is not considered the victim of others or the past unless he/she thinks this way. An important principle of the choice theory is that the past events may play a role in the present problem while it is never the problem per se. Regardless of what happened in the past, effective performance and timely planning are required at the present time and the individual should hold himself/herself responsible for the actions which are necessary to improve his/her current interpersonal relationships (13). Accordingly, it can be claimed that group reality therapy enables the group members to learn the appropriate behaviors required to meet their needs and to concentrate on the present instead of the past. Further, this approach probably increases hope whereas it reduces the irrational beliefs in the brilliant talent students.

Furthermore, positive psychotherapy helps the students rationally solve their problems, become flexible, and improve their quality of life calmly and thoughtfully. This approach plays a role in individuals' understanding of the fact that incidents are unstable and transient, enabling them to have constructive and non-mandatory thoughts about the unpleasant events and to trust in themselves in coping with the stressful problems (22). In this study, attribution style of the students or interpretations of the events were studied. The brilliant talent students learned how to identify their thoughts and feelings after different incidents and assess the correctness of their beliefs. These techniques helped the students investigate the effects of irrational beliefs and replace them with more logical ones.
It seems that both therapies reduced the irrational beliefs in two different ways by stressing self-assessment and selfconfidence.

Additionally, the results indicated that group reality therapy and positive psychotherapy enhanced psychological hardiness and their effects durability until the follow-up phase. In addition, no difference was observed between group reality therapy and positive psychotherapy in terms of improvement in psychological hardiness. In line with these findings, the findings of Gholami Heydarabadi et al (27) demonstrated the lack of any difference between the group reality therapy and positive psychotherapy interventions with respect to improving psychological hardiness. Based on the theoretical fundamentals, it can be argued that group reality therapy mainly emphasizes the acceptance of reality, responsibility, and the present time. As a result, the counselor helps the students assess their own behaviors and check whether these behaviors are useful. In the case of useless and impractical thoughts, they learn to control them and formulate a realistic plan for better behaviors so that they should be committed to their plans for achieving their goals. In addition, training of group reality therapy allows individuals to encounter with their problems in a healthy way, overcome the difficulties, and enjoy their lives since this type of therapy can result in developing a good mindset and enabling the individuals to learn how to identify their irrational and insensible assessments. In other words, it improves their psychological hardiness.

Further, regarding the effect of positive psychotherapy on psychological hardiness, it should be emphasized that unlike the other approaches which are focused on the problems, this approach seeks to improve the positive emotions and the quality of life (23). The positive emotions advocated by positive psychotherapy have an enormous potential for increasing the psychological hardiness and adaptation in the process of dealing with difficulties. Furthermore, the beliefs about psychological hardiness can be protective and reduce the stressful nature of the incidents. Additionally, positive psychotherapy helps the students control their actions and thoughts, devote their energy to their goals, take control of the situation, know that they determine (control) their lives, and view the changes as challenges and 
opportunities for growth and development (challenge) and attempt to influence and challenge the existing situation (25). Therefore, the positive factors in a person's life can compensate for some of the threats and as a result, they can interact with the other factors to reduce the negative consequences. Further, positive psychotherapy can prevent damage to psychological hardiness by reducing the negative symptoms, along with creating positive emotions, dispositions, and meaning effectively and directly. Eventually, such psychotherapy can create positive resources, undermine the negative syndromes, and prevent their reoccurrence.

\section{Conclusion}

Generally speaking, the group reality therapy and positive psychotherapy were similar in their effects on irrational beliefs and psychological hardiness. These outcomes result in extending the knowledge and therapeutic techniques for gifted students with different expectations and tendencies. Accordingly, it should be highlighted that both abovementioned interventions can be used for reducing the irrational beliefs while increasing psychological hardiness in exceptionally talented students. Furthermore, given that the gifted students are one of the most important human resources in every society, it is necessary to value the effective interventions for this particular group. As a result, specialists can employ group reality therapy and positive psychotherapy to create desirable positive changes in brilliant talent students. Additionally, it is noteworthy that this research was conducted only on the brilliant talent, male second grade, high school students in Shahrekord. Therefore, the results should be generalized with caution.

\section{Conflict of interests}

None.

\section{Acknowledgments}

This study was derived from a Ph.D. dissertation on psychology (research code: 13320705961012). Hereby, we gratefully thank the students, as well as the educational and administrative staff of the Brilliant Talents Center for their valuable help during the implementation of the present research project.

\section{References}

1. Emerick LJ. Academic Underachievement Among the Gifted: Students' Perceptions of Factors that Reverse the Pattern. Gifted Child Quarterly. 1992;36(3):140-6. doi: 10.1177/001698629203600304.

2. Berger J, Karabenick L, Stuart A. Motivation and students' use of learning strategies: Evidence of unidirectional effects in mathematics classrooms. Learning and Instruction 2001;21:416-28.

3. Terman LM. Genetic studies of genius: Vol. 1. Mental and physical traits of a thousand gifted children. Standford University Press; 1925.

4. Narimani M, Mohammad Amini Z, Barghmand A, Abu Al-Ghasemi A. The Relationship between Psychological Hardiness of Thinking Styles and Social Skills with Students' Academic Development. J Adv Psychol Res. 2007;2(5):10793. [Persian].
5. Kobasa SC. Stressful life events, personality, and health: an inquiry into hardiness. J Pers Soc Psychol. 1979;37(1):1-11.

6. Klag S, Bradley G. The role of hardiness in stress and illness: An exploration of the effect of negative affectivity and gender. Br J Health Psychol. 2004;9(Pt 2):137-61. doi: 10.1348/135910704773891014.

7. Mathis M, Lecci L. Hardiness and college adjustment: Identifying students in need of services. J Coll Stud Dev. 2015;40(3):305-9.

8. Wiebe DJ. Hardiness and stress moderation: a test of proposed mechanisms. J Pers Soc Psychol. 1991;60(1):89-99.

9. Shahpiri R, Isfahani Khaleghi A, Banakadi N. The prediction of various types of irrational beliefs with psychological hardiness of high school girl students in Tehran, second international congress on social empowerment in the field of social sciences, psychology and education. Tehran: Center for Empowerment of Social and Cultural Skills; 2016.

10. Moller AT, van der Merwe JD. Irrational beliefs, interpersonal perception and marital adjustment. J Ration Emot Cogn Behav Ther. 1997;15(4):269-79. doi: 10.1023/a:1025089809243.

11. Mahin Torabi S, Mazaheri MA, Sahebi A, Mousavi V. The Effect of Cognitive-Behavioral Training on Adjustment of Irrational Expectations, Emotional Maturity, and Marital Dissatisfaction in Women. Journal of Behavioral Sciences. 2009;5(2):127-33. [Persian].

12. Hayes SC, Strosahl KD, Wilson KG. Acceptance and commitment therapy: The process and practice of mindful change. 2nd ed. New York: Guilford Press; 2012.

13. Wubbolding RE. Reality therapy: Theories of psychotherapy series. Washington, DC: American Psychological Association; 2011.

14. Loyd BD. The effects of Choice Theory/Reality Therapy principles on high school students' perception of needs satisfaction and behavioral change. International Journal of Reality Therapy. 2005;66(1-A):96.

15. Golestan A, Mirfakhraei A. The Effectiveness of Glaser's Reality Therapy on Ineffective and Ridicular Attitudes of Patients with MS in Kazeroon, The Third Conference of Positive Journal Psychology. Bandar Abbas: Islamic Azad University, Bandar Abbas Branch; 2017.

16. Maldari F, Masoudi S. The Effectiveness of the Reality of Therapy on the Irrational Implications of Exceptional Mothers, Fourth National Conference on Mental Health and Consultation. Quchan: Islamic Azad University, Quchan Branch; 2016.

17. Mesmanabadi M, Heidari H, Mir Mahdi R, Al Yasin R, Mazlomi A. The effectiveness of group-based reality-based therapy counseling on the self-control and resilience of women with a disabled child in Arak. The International Conference on the Humanities, Psychology and Social Sciences; 2013.

18. Safavi Gordani AS, Bahrainan A, Shahabizadeh F. Effect of Group Therapy on Resilience and Psychological Strengthening of High School Students in Kerman. Second National Conference on Psychology and Behavioral Sciences; 2012.

19. Peterson AV, Chang C, Collins PL. The effects of reality therapy and choice theory training on self concept among Taiwanese university students. International Journal for the Advancement of Counselling. 1998;20(1):79-83. doi: 10.1023/a:1005340014026.

20. Kim JU. The effect of a R/T group counseling program on the Internet addiction level and self-esteem of Internet addiction university students. International Journal of Reality Therapy. 2008;27(2):4-12.

21. Alberto J, Joyner B. Hope, optimism, and self-care among Better Breathers Support Group members with chronic obstructive pulmonary disease. Appl Nurs Res. 2008;21(4):212-7. doi: 10.1016/j.apnr.2006.12.005.

22. Peterson C, Seligman M. Character Strength and Virtues: 
A Handbook and Classification. American Psychological Association, Oxford University Press; 2006.

23. Pollner M. Divine relations, social relations, and well-being. J Health Soc Behav. 1989;30(1):92-104.

24. Fredrickson BL. The role of positive emotions in positive psychology: The broaden-and-build theory of positive emotions. Am Psychol. 2001;56:218-26.

25. Fredman R, James F, Kafller L, Goldberg $\mathrm{S}$. The role of meaning in life and optimism in promoting well-being. The Chinese University of Hong Kong: Shatin, University of Macau, China; 2016.

26. Arjomandnia AS, Vatani S, Hassanzadeh S. The Effect of Positive Teaching Skills on Happiness and Irrational Beliefs of the Students of the Blind. Positive Psychological Research. 2017;2(3):21-34. [Persian]

27. Gholami Heydarabadi Z, Nawbi Nejad S, Shafi Abadi, Delaware A. The Effectiveness of Reality Therapy and Positive Behavioral Training on the Increased Hardship of Mothers with the Blind Child. J Educ Manag Res. 2013;4(3):57-76. [Persian]

28. Glasser W. Reality Therapy in Action. New York: Harper Collins; 2001.

29. Seligman ME, Csikszentmihalyi M. Positive psychology. An introduction. Am Psychol. 2000;55(1):5-14.

30. Jones RG. A factored measure of Ellis's irrational beliefs with personality and maladjustment correlates. Texas: Technological College; 1968.

31. Babaei S, Rezahani SD. Effectiveness of therapeutic reality on increasing academic motivation and social adjustment of girls. Educational Management Research. 2017;8(31):117128. [Persian].

32. Kobasa SC. Hardiness in Lindsey, Thompson and spring (Eds) psychology. 3rd ed. New York: Worth Publishers; 1988.

33. Kobasa SC. Stressful life events, personality, and health: an inquiry into hardiness. J Pers Soc Psychol. 1979;37(1):1-11.

34. Narimani $M$, Abbasi $M$. Investigating the relationship between psychological hardiness and self-esteem with burnout. Beyond Management. 2009;2(8):75-92. [Persian].

35. Jamhari $\mathrm{F}$. The study of the relationship between hardiness and tendency to depression and anxiety among female and male students of Tehran universities [thesis]. Tehran: Allameh
Tabatabaei University; 2000. [Persian].

36. Sedaghat M, Sahebi A, Shahabi Moghadam S. The Effectiveness of Reality Therapy in a Case Method on Suffering Suicidal Persons with Substantive Depression. J Med Sci. 2014;5(5):371-378. [Persian].

37. Noferesti A, Roshan R, Fathi L, Hassan Abadi H, Pasandide A, Shoeyri MA. The Effectiveness of Positive Psychotherapy on Happiness and Psychological Well-being of People with Depression Symptoms: Single Student Study with Multiple Basic Lines. Positive Psychological Research. 2013;1(1):1-18. [Persian].

38. Touzandeh Jani $\mathrm{H}$, Soltanzadeh $\mathrm{H}$. Effectiveness of Reality Therapy on Depression in Infertile Women before IUI Fertility Assistance. J Res Behav Sci. 2012;12(2):44-54. [Persian].

39. Jabbari M, Shahidi S, Motabi F. Investigating group positive attitudes in reducing inefficient attitudes and increasing the level of happiness among adolescent girls. J Clin Psych. 2012;6(2):65-74. [Persian].

40. Kwok SYCL, Gu M, Kit KTK. Positive psychology intervention to alleviate child depression and increase life satisfaction: A randomized clinical trial. Res Soc Work Pract. 2016;26(4):35061. doi: 10.1177/1049731516629799.

41. Proyer RT, Gander F, Wellenzohn S, Ruch W. Strengths-based positive psychology interventions: a randomized placebocontrolled online trial on long-term effects for a signature strengths- vs. a lesser strengths-intervention. Front Psychol. 2015;6:456. doi: 10.3389/fpsyg.2015.00456.

42. Bolier L, Haverman M, Westerhof GJ, Riper H, Smit F, Bohlmeijer E. Positive psychology interventions: a metaanalysis of randomized controlled studies. BMC Public Health. 2013;13:119. doi: 10.1186/1471-2458-13-119.

43. Bhargava R. The use of reality therapy with a depressed deaf adult. Clin Case Stud. 2013;12(5):388-96. doi: 10.1177/1534650113496869.

44. Prenzlau S. Using Reality Therapy to Reduce PTSDRelated Symptoms. International Journal of Reality Therapy. 2006;25(2):23-29

45. Seligman ME, Steen TA, Park N, Peterson C. Positive psychology progress: empirical validation of interventions. Am Psychol. 2005;60(5):410-21. doi: 10.1037/0003-066x.60.5.410. 